NBER WORKING PAPER SERIES

\title{
EQUILIBRIUM POLICY EXPERIMENTS AND THE EVALUATION OF SOCIAL PROGRAMS
}

\author{
Jeremy Lise \\ Shannon Seitz \\ Jeffrey Smith \\ Working Paper 10283 \\ http://www.nber.org/papers/w10283
NATIONAL BUREAU OF ECONOMIC RESEARCH 1050 Massachusetts Avenue
Cambridge, MA 02138
January 2004

\begin{abstract}
We are grateful for helpful comments from Marina Adshade, David Andolfatto, Dan Black, Stephen Coate, Curtis Eaton, Chris Ferrall, John Ham, Allen Head, Robert Moffitt, Derek Neal, Chris Taber, Petra Todd, Jim Walker, and Ken Wolpin, along with participants at the 2001 Canadian Economic Association Meetings, the 2003 Canadian Public Economics Study Group, the 2003 Econometric Society Winter Meetings, the 2003 Institute for Research on Poverty Summer Workshop, the 2003 IZA/SOLE Transatlantic Meetings, the 2002 Society of Labor Economists Meeting, and the World Bank, and seminar participants at the following universities: British Columbia, Carnegie-Mellon, Cornell, Guelph, Mannheim, McMaster, Melbourne, North Carolina at Greensboro, Pennsylvania, Queen's, Simon Fraser, Toronto and Tulane. We thank Andrew Leach for excellent research assistance. Financial support from the Social Research and Demonstration Corporation is gratefully acknowledged. The views expressed herein are those of the authors and not necessarily those of the National Bureau of Economic Research.
\end{abstract}

(C2004 by Jeremy Lise, Shannon Seitz, and Jeffrey Smith. All rights reserved. Short sections of text, not to exceed two paragraphs, may be quoted without explicit permission provided that full credit, including (C) notice, is given to the source. 
Equilibrium Policy Experiments and the Evaluation of Social Programs

Jeremy Lise, Shannon Seitz, and Jeffrey Smith

NBER Working Paper No. 10283

January 2004

JEL No. J2, I38, J6

\section{$\underline{\text { ABSTRACT }}$}

This paper makes three primary contributions. First, we demonstrate the usefulness of general equilibrium models as tools with which to draw policy implications for policies implemented in practice only as small-scale social experiments. Second, we illustrate the usefulness of social experiments as a tool to evaluate equilibrium models. In particular, we calibrate our model using only data on an experimental control group and from general data sets, and then use it to predict (in partial equilibrium) the outcomes experienced by an experimental treatment group. We find that it predicts these outcomes remarkably well. Third, we apply our methodology to the evaluation of the Canadian Self-Sufficiency Project (SSP), a policy providing generous financial incentives for Income Assistance (IA) recipients to obtain stable employment. This policy is similar to many other policies designed to "make work pay" currently under debate or in place in the US, the UK and elsewhere. Our results reveal several important feedback effects associated with the SSP policy; taken together, these feedback effects reverse the cost-benefit conclusions implied by the partial equilibrium experimental evaluation.

Jeremy Lise

Department of Economics

Queen's University

lise@econ.queensu.edu
Shannon Seitz

Department of Economics

Queen's University

seitz@post.queensu.edu
Jeffrey Smith

Department of Economics

University of Maryland

3105 Tydings Hall

College Park, MD 20742

and NBER

smith@econ.umd.edu 


\section{Introduction}

Many potential policies have been evaluated using social experiments, where small subsets of the population are randomly assigned to treatment and control groups, the treatment group is subjected to the potential policy reform and the difference in outcomes between the groups provides an estimate of the mean impact of the policy. The resulting treatment effects literature provides useful estimates of the effect of treatment on those individuals participating in the program within an experiment, where typically a small number of individuals are affected by the policy. However, such estimates may be of limited usefulness if the policy evaluated in the experiment is implemented in general. A growing body of research indicates that a policy may have very different implications when it is implemented for the general population than when it is implemented on only a small number of participants for evaluation purposes.

As outlined in Calmfors (1994) and elsewhere, such general equilibrium effects of programs represent a critical component of social cost-benefit analysis. Consider two examples of such effects. First, programs may have indirect effects on both participants and nonparticipants by changing the equilibrium of the labor market. These effects violate the "stable unit treatment value assumption" (SUTVA) invoked to justify partial equilibrium analysis. Heckman, Lochner, and Taber (1998) consider increasing subsidies to college tuition and find that the resulting increase in the number of individuals who attend college has the effect of increasing the supply of college graduates and reducing their wages. In this case, the effect of the tuition policy depends on the number of college graduates in the labor market.

Second, programs may directly affect those who are not treated within the program. As discussed by Heckman and Smith (1998), the standard treatment effects literature assumes 
that the outcomes for individuals not treated by the program within an experiment are the same as the outcomes non-participants would experience if the program were implemented more widely. This need not be the case. For example, consider the US Unemployment Insurance Bonus experiments, where individuals starting a spell of unemployment were offered a cash payment if they obtained employment within a limited time period. Davidson and Woodbury (1993) estimate the displacement effects of the bonus program that would result from changes in the search behavior of all workers in the labor market. In particular, the bonus increases the gain to employment for workers eligible to receive it, resulting in increased search effort and employment. Some of the increase in employment will be in jobs that would otherwise have been held by workers not eligible for the bonus. This displacement directly affects a subset of the labor force not treated within the program.

Existing studies, such as those mentioned above, indicate that the equilibrium effects of large-scale policies may be substantial. With regard to the college tuition subsidies studied by Heckman, Lochner and Taber (1998), they estimate that the general equilibrium effects on enrollment rates are 10 times smaller than those obtained from a partial equilibrium analysis. Davidson and Woodbury (1993) estimate that the displacement of UI-ineligible workers offsets 30-60 percent of the gross employment effect of the bonus program. This has a strong effect on the estimated net impact of the program from society's point of view. In recent work, Blundell, Costa Dias, and Meghir (2003) consider the long-run effects of a largescale wage subsidy policy for low-skill workers. They find that the general equilibrium effects of the policy on unemployment are opposite in sign to the predictions of a partial equilibrium analysis. Overall, the literature shows that general equilibrium program evaluations can lead to very different conclusions regarding the cost-benefit performance of labor market policies.

Studying the potential general equilibrium effects that may result from implementing a small-scale social experiment as a large-scale policy is difficult without the use of an equi- 
librium model. However, the degree of confidence that can be placed in policy experiments generated within a model depends to a large extent on how well the model captures the behavior of the individuals affected by the policy.

The goal of our paper is to combine the advantages of the literature that attempts to evaluate potential policies through social experiments with the literature that evaluates potential policies through model experiments. We construct a dynamic, equilibrium model that is well-suited for conducting labor market policy experiments and we use the model as a tool for evaluating social programs. Our model is based on the search model of Davidson and Woodbury (1993). Within the model, the amount of time required to find a job can be reduced by increased search effort on the part of the worker. Once workers and firms meet, they bargain over wages in an environment where wages reflect the value of the match and the value of the outside options faced by both parties. This framework is ideally suited for many equilibrium program evaluations, as it explicitly considers the effect of changes in financial incentives introduced by social programs on the intensity with which individuals search for jobs and on the process by which wages are determined in the labor market. In addition to the matching and wage determination process, our model incorporates key features of the Income Assistance (IA) and Unemployment Insurance (UI) programs, both of which constitute important aspects of the economic context and are likely to have important feedback effects on the labor market.

We demonstrate the usefulness of social experiments as tools to evaluate equilibrium models. In this respect, our paper serves as an analogue to work by Lalonde (1986) and others, where experiments are used as a benchmark against which to assess the performance of partial equilibrium non-experimental estimators. ${ }^{1}$ In particular, we test our model by examining its ability to match the observed behavior of the experimental treatment group

\footnotetext{
${ }^{1}$ See, e.g., Smith and Todd (2004) for a summary of this literature.
} 
when calibrated using only the experimental control group (and external data).

In general, calibrated models are tested by examining the extent to which they can replicate features of the economy. Our exercise is more stringent in the sense that the model must also be able to match the behavior observed in the data following a policy change without exploiting the variation introduced by the policy change itself. We are able to replicate the outcomes produced by a social experiment without using the data from the experimental treatment group. The ability of the model to do so greatly increases our confidence in the results from our general equilibrium program evaluation. In parallel work, Todd and Wolpin (2003) use the data from the experimental evaluation of Mexico's PROGRESA program to test a partial equilibrium, structural, dynamic model of fertility and child schooling using a similar approach. Their model does a good job of matching the experimental impacts from PROGRESA.

We apply our methodology to the equilibrium evaluation of the Canadian Self-Sufficiency Project (SSP), a policy designed to provide incentives for individuals on income assistance to leave the system for full-time employment. ${ }^{2}$ Similar, but less generous, income supplement programs have been studied in the United States; see Auspos, Miller, and Hunter (2000) on the Minnesota Family Investment Program and Bos, Huston, Granger, Duncan, Brock, and McLoyd (1999) on the Wisconsin New Hope program. Bloom and Michalopoulos (2001) provide an overview of the experimental literature and compare these programs to other approaches. These programs, along with policies such as the Earned Income Tax Credit (EITC) in the US and the Working Families Tax Credit (WFTC) in the UK, aim to "make work pay" by subsidizing low-wage work.

The SSP provides financial incentives by offering a temporary earnings supplement to

\footnotetext{
${ }^{2}$ A growing literature looks at various aspects of the Self-Sufficiency Project. See, e.g., Card and Hyslop (2002), Ferrall (2000) and Kamionka and Lacroix (2002).
} 
single parents on IA. $^{3}$ Individuals must remain on IA twelve months to become eligible for the earnings supplement; once they do, they receive a supplement if they obtain fulltime employment (at least 30 hours per week) and leave IA within the following twelve months. The supplement equals half the difference between the individual's earnings and a province-specific cutoff level in each month.

Our model incorporates the main features of the SSP. In particular, the model allows for time limits in determining eligibility for receipt of the supplement, consistent with the one-year time limit in the experiment, allows individuals to receive the earnings supplement for up to three years while employed, and allows the earnings supplement to depend on the wages received by eligible recipients. The full-time work requirement is the sole omission, due to the fact that our model does not include the hours choice. In addition, our model incorporates the time limitations on entry and exit in the Canadian unemployment insurance ${ }^{4}$ program and captures the interactions between IA, UI and the minimum wage in the labor market.

After constructing the model, we adopt the following strategy. First, we calibrate the equilibrium model in the absence of the program using publicly available, non-experimental data and data on the experimental control group. The parameters calibrated in the first stage include the discount rate, search friction parameters, and exogenous job separation rates: parameters that are, in theory, invariant to changes in the income assistance program. Using the calibrated model, we simulate a model control group.

Second, we simulate the SSP experiment within our calibrated model using the param-

\footnotetext{
${ }^{3}$ In Canada, IA provides mean-tested transfers to persons of working age that do not depend on past earnings or employment but do depend on family size and composition. Canada also has an unemployment insurance system (similar to that in the US but more generous) that pays benefits that depend on past earnings and employment (but not on family size or composition) to workers with sufficient past employment. Unemployment insurance is the more generous program, so a worker eligible for both will collect that first until his or her eligibility runs out, and then switch to IA.

${ }^{4}$ The Canadian UI program is presently called Employment Insurance; we use the standard international term here for clarity.
} 
eters obtained in the first stage. A simulated treatment group is constructed by imposing the Self-Sufficiency Project in partial equilibrium.

Third, we compare the impacts from the simulated treatment and control groups to those from the SSP social experiment, in order to determine how well our model replicates the observed treatment effects. The results from this exercise lend strong support to our parsimonious model, as the simulated treatment group outcomes match the experimental data quite closely. In particular, the IA-to-work transition rates for the simulated treatment group during the 36 months following random assignment are virtually the same as those observed in the experimental data. We are also able to match the delayed exit effects of a second randomized experiment that offered SSP to new IA recipients.

Fourth, we re-calibrate the model using data on the low-skill population as a whole, and simulate the equilibrium effects that result from introducing the SSP as a general policy for all IA recipients, not just single mothers. Our model allows us to quantify the displacement, wage and delayed exit effects of the SSP and provides a more complete picture of the potential implications of implementing the SSP as policy than does the partial equilibrium experimental evaluation.

Four main results emerge from the equilibrium program evaluation. First, introducing an earnings supplement to the income assistance program has implications for unemployed workers, as the increase in employment for IA recipients coincides with a decrease in reemployment rates for those individuals receiving UI benefits. As a result, the overall employment level does not change after the introduction of the policy. Second, although the introduction of an earnings supplement increases the rate of exits to employment from IA, it does so at lower equilibrium wages, as workers are willing to accept lower starting wages so as to benefit from the supplement payments. Surprisingly, the wages of other workers in the economy increase slightly, as the increased value of IA due to the introduction of the 
earnings supplement increases the fraction of the match surplus transferred to the worker. This result is primarily due to the fact that the minimum wage limits the ability of firms to extract the surplus generated by the supplement from the worker. Third, the simulation results indicate the presence of entry and delayed exit effects, as the transition rate into the IA program from UI increases and a higher fraction of individuals remain on IA long enough to qualify for the supplement after the policy change. Fourth, taken together, the equilibrium effects reverse the cost-benefit conclusions from the partial equilibrium analysis and further illustrate the importance of equilibrium program evaluation.

\section{The Model}

In this section, we present the model of the labor market that we use to conduct equilibrium program evaluations. Three segments of the market are incorporated in the model: individuals may be employed $(E)$, unemployed and receiving UI benefits $(U)$ or on income assistance $(A) .^{5}$ This feature of the model allows us to consider how workers, unemployed individuals and income assistance recipients interact in the labor market. The model builds on the equilibrium search model of Davidson and Woodbury (1993), where individuals maximize expected lifetime income by choosing their labor market state and the intensity with which they search for work if not employed. ${ }^{6}$ We extend Davidson and Woodbury (1993) to incorporate the income assistance program, minimum wages, and time limitations for entry to and exit from the unemployment insurance program. Workers bargain with firms over wages that depend on the tenure of the match, the minimum wage, and on the outside options of both parties. Through this channel, the model generates predictions regarding the way starting wages vary depending on the state from which the individual enters em-

\footnotetext{
${ }^{5}$ Throughout this paper we use the term unemployed to mean collecting UI benefits. In the model, all jobless individuals are actively seeking employment; they are distinguished by whether they are receiving unemployment benefits or income assistance benefits.

${ }^{6}$ The model of Davidson and Woodbury (1993) is based on work by Diamond (1982), Mortensen (1982) and Pissarides (1984).
} 
ployment. It is further assumed that the value of the match surplus increases with job tenure, generating on-the-job wage growth in the model.

Our model incorporates key features of typical unemployment insurance and income assistance programs. ${ }^{7}$ First, individuals face time limitations regarding entry to and exit from the unemployment insurance system. Individuals who enter employment from income assistance or who have exhausted their unemployment benefits become eligible to receive unemployment benefits after $I$ months of employment. The number of months of benefit eligibility subsequently increases by one month for each additional month of employment, from a minimum of $\underline{u}$ months up to a maximum of $\bar{u}$ months. Workers who enter employment with unused benefits retain their unused benefit months and accumulate additional months with each month worked. Second, individuals who exhaust their UI benefits and do not secure a job are assumed to transit directly to income assistance. Finally, it is assumed that individuals can remain on income assistance indefinitely or transit to employment if they contact a firm with a vacancy; income assistance recipients cannot transit directly from IA to unemployment. In the following sections, we describe the problems faced by each type of individual and by firms in the model.

\subsection{Workers}

The value of employment for a worker depends on her job tenure $t$ and unemployment insurance benefit eligibility status $i$, where $i \in\{0,1, \ldots, \underline{u}, \ldots, \bar{u}\}$. The number of months an individual with no benefits must work in order to qualify for UI benefits is $I$. For every period an individual works beyond $I, i$ increases by 1 . The maximum number of benefit months an individual can accumulate is denoted $\bar{u}$. If an individual is not working she would

\footnotetext{
${ }^{7}$ The program details correspond to those in place in Canada at the time of the SSP experiment. Our model could easily be modified to correspond to the institutions present in the US, the UK, or other developed countries.
} 
therefore be unemployed with $i$ periods of benefits remaining. ${ }^{8}$ With probability $\delta$, jobs are exogenously destroyed in the subsequent month, in which case workers transit to income assistance if they have not yet qualified for UI benefits $(i=0)$ and transit to unemployment otherwise. With probability $(1-\delta)$, workers remain employed in the next month.

It is assumed that individuals who return to work before their UI benefits expire retain their remaining UI benefit eligibility. Finally, workers experience on-the-job wage growth for a maximum of $T$ months, after which the wage remains constant, where it is assumed that $T>\bar{u}$. The value function for a worker with outside option $i$ and with job tenure $t$ is:

$$
V^{E}(t, i)= \begin{cases}w(t, 0)+\beta\left[(1-\delta) V^{E}(t+1,0)+\delta V^{A}\right] & \text { if } t<I \text { and } i=0, \\ w(t, 0)+\beta\left[(1-\delta) V^{E}(t+1, \underline{u})+\delta V^{U}(\underline{u})\right] & \text { if } t=I \text { and } i=0, \\ w(t, i)+\beta\left[(1-\delta) V^{E}(t+1, i+1)+\delta V^{U}(i+1)\right] & \text { if } 0<i<\bar{u} \text { and } I \leq t<T, \\ w(t, \bar{u})+\beta\left[(1-\delta) V^{E}(t, \bar{u})+\delta V^{U}(\bar{u})\right] & \text { if } i=\bar{u} \text { and } I \leq t<T, \\ w(T, \bar{u})+\beta\left[(1-\delta) V^{E}(T, \bar{u})+\delta V^{U}(\bar{u})\right] & \text { if } t \geq T,\end{cases}
$$

where $w(t, i)$ is the wage for a person with tenure $t$ who has $i$ months of UI benefit eligibility remaining, $\beta$ is the discount rate, $V^{A}$ is the value of being on income assistance, and $V^{U}(i)$ is the value of being unemployed with $i$ periods of UI benefits remaining.

\section{$2.2 \quad$ IA Recipients}

IA recipients receive benefits $\left(b_{a}\right)$ and pay search costs $c_{a}\left[p(0)^{z}\right]$ every month they remain on IA, where $z$ is the elasticity of search costs with respect to search effort, $c_{a}$ is a parameter capturing the disutility of search effort, and $p(i)$ is the optimal search effort for individuals with $i$ months of UI benefits remaining (and also the probability that such a worker contacts a firm). The cost of search depends directly on the intensity with which individuals search. In particular, for values of $z>1$, the marginal cost of search increases as search effort increases. If IA recipients match with a firm, they transit to employment. Otherwise, they

\footnotetext{
${ }^{8}$ The UI system in our model embodies two simplifications relative to the system in place at the time of the SSP experiment. First, months of employment do not cumulate across job spells in determining benefit eligibility. Second, months of benefit eligibility last indefinitely once obtained. Both simplifications substantially reduce the state space of the model.
} 
remain on IA in the next period. The value function for an IA recipient is

$$
V^{A}=\max _{p(0)}\left\{b_{a}-c_{a}\left[p(0)^{z}\right]+\beta\left[m(0) V^{E}(1,0)+(1-m(0)) V^{A}\right]\right\}
$$

where $m(0)$ is the match rate for IA recipients, which depends in part on the search effort $p(0)$. The only reason IA recipients are not employed is because an employment opportunity is not available and the only way an IA recipient can increase the likelihood of finding a job is through increased search effort. ${ }^{9}$

\subsection{Unemployed Individuals}

Unemployed agents receive exogenous UI benefits $\left(b_{u}\right)$ and pay search $\operatorname{costs} c_{u}\left[p(i)^{z}\right]$. We make the simplifying assumption that unemployment benefits are independent of the individual's pre-separation earnings. With probability $m(i)$, individuals contact a firm with a vacancy and transit to employment in the next month. If individuals remain unemployed in the next month, it is assumed they continue to collect UI benefits. Following the last month of UI benefit eligibility, individuals can either transit to employment, if a job opportunity is available, or transit to IA. The value function for unemployed individuals with $i$ months of benefits remaining is

$V^{U}(i)= \begin{cases}\max _{p(i)}\left\{b_{u}-c_{u}\left[p(i)^{z}\right]+\beta\left[m(i) V^{E}(1, i-1)+(1-m(i)) V^{U}(i-1)\right]\right\} & 1<i \leq \bar{u}, \\ \max _{p(i)}\left\{b_{u}-c_{u}\left[p(i)^{z}\right]+\beta\left[m(1) V^{E}(1,0)+(1-m(1)) V^{A}\right]\right\} & i=1 .\end{cases}$

\subsection{Firms}

Production takes place when there is a match between one firm and one worker; the number of firms can alternatively be interpreted as the number of jobs in the economy. In every

\footnotetext{
${ }^{9}$ It is worth noting that we assume all income assistance recipients enter employment with zero tenure. This assumption could be relaxed by assuming workers retain their experience when they enter income assistance and then allowing their experience to depreciate over time. One implication of this extension would be that the hazard of leaving IA would decline as the length of the IA spell increased. The drawback of this extension is that it involves a large increase in the size of the state space. We thank Jim Walker for this valuable suggestion.
} 
period, each firm has the option of filling a vacancy, if one exists, by hiring a worker or keeping the vacancy open. If matched with a worker, firms earn profits that depend on the surplus generated by the match and pay wages, determined in equilibrium, that depend on the worker's outside options and the minimum wage. Profits depend on the worker's tenure in order to allow match-specific capital to increase the productivity of the match over time. Denote the surplus generated by a worker-firm pair of tenure $t$ by $S(t)$. With probability $\delta$ the match separates and the firm is left with a vacancy in the following month. Denote the profits of a firm matched with a worker with outside option $i, i \in\{0,1, \ldots, \underline{u}, \ldots, \bar{u}\}$ and match tenure $t$ as $\Pi(t, i)$.

The expected discounted present value of profits for matches of job tenure $t$ and workers with outside option $i$ are

$$
\Pi^{E}(t, i)=S(t)-w(t, i)+ \begin{cases}\beta\left[\delta \Pi^{V}+(1-\delta) \Pi^{E}(t+1,0)\right] & \text { if } i=0 \text { and } t<I, \\ \beta\left[\delta \Pi^{V}+(1-\delta) \Pi^{E}(t+1, \underline{u})\right] & \text { if } i=0 \text { and } t=I, \\ \beta\left[\delta \Pi^{V}+(1-\delta) \Pi^{E}(t+1, i+1)\right] & \text { if } 0<i<\bar{u} \text { and } t<T, \\ \beta\left[\delta \Pi^{V}+(1-\delta) \Pi^{E}(t+1, \bar{u})\right] & \text { if } i=\bar{u} \text { and } t<T, \\ \beta\left[\delta \Pi^{V}+(1-\delta) \Pi^{E}(T, \bar{u})\right] & \text { if } t \geq T,\end{cases}
$$

where match tenure beyond $T$ no longer increases profits.

If a firm has a vacancy, the value of the vacancy is determined by the probability of meeting an unmatched worker, by the profits the firm expects to make from the match, and by the costs of posting a vacancy $(\xi)$

$$
\Pi^{V}=-\xi+\beta\left[\sum_{i=0}^{\bar{u}} q(i) \Pi^{E}(1, i)+\left(1-\sum_{i=0}^{\bar{u}} q(i)\right) \Pi^{V}\right],
$$

where $q(i)$ is the probability a firm matches with a worker with outside option $i$. Firms will post vacancies unless the expected profit from doing so is negative. We assume free entry, so that in the steady state equilibrium the number of firms in the economy will be determined by the condition that the expected profits from posting a vacancy equal zero. 


\subsection{Search Technology}

Assume, for simplicity, that there is no on-the-job search in the economy. The probability that a jobless individual receives a job offer depends on the probability the worker contacts a firm and the probability a firm has a vacancy.

\subsubsection{Workers}

The probability a firm has a vacancy is simply the total number of vacancies divided by the total number of firms

$$
\frac{V}{F}
$$

If a firm has a vacancy, it will hire a worker and pay a wage which is the outcome of Nash bargaining between the worker and the firm, discussed in detail below. Applications for jobs arrive according to a Poisson process, where $\lambda$ is the average number of applications filed by workers at each firm. Firms with more than one applicant randomly draw a worker from the applicant pool. ${ }^{10}$ The probability a worker is offered a job is:

$$
\frac{1-e^{-\lambda}}{\lambda}
$$

The conditional re-employment probabilities for unemployed workers and workers on income assistance can then be expressed as the product of the above components, multiplied by the worker's search effort

$$
m(i)=\frac{p(i) V}{\lambda F}\left(1-e^{-\lambda}\right)
$$

where

$$
\lambda=\frac{1}{F}\left(\sum_{i=1}^{\bar{u}} p(i) U(i)+p(0) A\right) .
$$

\footnotetext{
${ }^{10}$ Alternatively, we could let the length of a period tend to zero and work in continuous time, where there is zero probability of more than one application arriving at a given time. As we wish to take the model to data, we work with discrete periods.
} 
Workers determine the optimal level of search effort by equating the marginal benefit from an increase in search effort with its marginal cost. ${ }^{11}$ The optimal level of search effort, for each labor market state and program eligibility combination, is described by:

$$
\begin{aligned}
p(0) & =\left(\frac{\beta m(0)}{c_{a} z}\left[V^{E}(1,0)-V^{A}\right]\right)^{\frac{1}{z}}, \\
p(1) & =\left(\frac{\beta m(1)}{c_{u} z}\left[V^{E}(1,0)-V^{A}\right]\right)^{\frac{1}{z}}, i=1, \\
p(i) & =\left(\frac{\beta m(i)}{c_{u} z}\left[V^{E}(1, i-1)-V^{U}(i-1)\right]\right)^{\frac{1}{z}}, 1<i \leq \bar{u} .
\end{aligned}
$$

\subsubsection{Firms}

From the firm's perspective, the probabilities of matching with potential workers from unemployment and IA equal the numbers of workers from unemployment and IA who transit to employment, divided by the total number of vacancies, so that

$$
q(i)=\frac{m(i) U(i)}{V} \quad \text { and } \quad q(0)=\frac{m(0) A}{V}
$$

respectively.

\subsection{Equilibrium Wage Determination}

After meeting in the labor market, a firm and a worker bargain over wages by making alternating wage offers until both sides find the offer acceptable. It is assumed that the parties have equal bargaining power, but may have different threat points. The equilibrium of this game is the Nash cooperative bargaining solution and results in workers and firms splitting the surplus of a match evenly. The surplus of the match from the worker's perspective is the difference between employment at the equilibrium wage and the worker's outside option, which depends on their current labor market state and program eligibility. The surplus

\footnotetext{
${ }^{11}$ In determining the marginal cost and benefit of search effort $\lambda$ is held constant under the assumption that each worker believes her impact is small relative to the labor market as a whole.
} 
from the perspective of the firm is the difference between the profits the firm receives at the equilibrium wage and the value of leaving the vacancy open. It is further assumed that the bargaining process is constrained such that the wage can not fall below the minimum wage $\underline{w}$. The equilibrium wage, $w(t, i)$, equals the solution to

$$
[w(t, i)-\underline{w}]\left[\left(V^{E}(t, i)-V^{i}\right)-\left(\Pi^{E}(t, i)-\Pi^{V}\right)\right]=0
$$

subject to $[w(t, i)-\underline{w}] \geq 0$, where $V^{i} \in\left\{V^{A}, V^{U}(i)\right\}$ is the value of outside option $i$.

\subsection{Steady State Conditions}

Let $E$ denote the steady state number of jobs occupied by workers and $V$ the number of vacancies. By definition, the total number of jobs in the labor market is equal to the total number of occupied jobs and the total number of vacancies

$$
F=E+V
$$

Denote the total number of individuals in the labor market $L$. The total number of individuals can be decomposed into three groups. The first group consists of the employed, who are distinguished both by their current job tenure and their current outside option

$$
E=\sum_{t=1}^{T} \sum_{i} E(t, i)+\bar{E},
$$

where $\bar{E}$ is the group of workers no longer experiencing on-the-job wage growth. The second group, denoted $A$, consists of those on income assistance. The final group, denoted $U$, consists of unemployed individuals, who can receive UI benefits for a maximum of $\bar{u}$ periods

$$
U=\sum_{i=1}^{\bar{u}} U(i),
$$

where $U(i)$ indicates the number of unemployed persons with $i$ periods of benefits remaining.

The total number of individuals in the labor market is the sum of the three components

$$
L=E+A+U .
$$


Using these definitions, we can describe the conditions governing the steady state, where the flows in and out of every employment state must be equal over time. We now discuss the steady state conditions for each state and eligibility combination in turn.

\section{Employment}

As above, let $m(0)$ and $m(i)$ denote the probabilities that IA recipients and unemployment recipients with $i$ periods of benefits remaining, respectively, match with a firm. The flow into the first period of employment includes those workers from IA and unemployment who receive job offers. They are indexed by their respective outside options as this will determine their progression of benefit entitlements. In subsequent periods, the inflow consists of workers who were employed in the previous period and who were not exogenously separated from their jobs. Formally,

$$
\begin{aligned}
E(1,0) & =m(0) A+m(1) U(1) ; \\
E(1, i) & =m(i+1) U(i+1), \quad 0<i<\underline{u} ; \\
E(t, 0) & =(1-\delta) E(t-1,0), \quad 1<t<I \text { and } i=0 ; \\
E(t, i) & =(1-\delta) E(t-1, i-1), \quad 1<t<T \text { and } 0<i \leq \bar{u} ; \\
E(t, \bar{u}) & =(1-\delta) E(t-1, \bar{u}), \quad 1<t<T \text { and } i>\bar{u} ; \\
\delta \bar{E} & =(1-\delta) E(T, \bar{u}), \quad t \geq T .
\end{aligned}
$$

\section{Income Assistance}

The flow into IA includes those employed workers who were exogenously separated from their jobs and ineligible for UI benefits and unemployed workers no longer eligible for UI benefits. The flow out of IA includes IA recipients who find employment. The steady state condition for IA is the following:

$$
\delta \sum_{t=1}^{I} E(t, 0)+(1-m(1)) U(1)=m(0) A .
$$




\section{Unemployment}

Employed workers who are separated from their jobs and who are eligible for the maximum months of UI benefits flow into the first period of unemployment, $U(\bar{u})$. For $U(i)$ where $0<i<\bar{u}$, the inflow consists of unemployed workers from the previous period who did not find jobs, and workers separated from their jobs who qualify for less than the maximum number of benefit months. All workers flow out of the unemployment state when benefits run out due to the time limitations in the UI program

$$
\begin{aligned}
\delta \sum_{t} E(t, \bar{u}) & =U(\bar{u}) \\
\delta \sum_{t} E(t, i-1)+(1-m(i+1)) U(i+1) & =U(i) \quad \text { if } 0<i<\bar{u} .
\end{aligned}
$$

\section{Combining Social Experiments and Structural Models for Policy Evaluation}

In this section, we describe a way to use social experiments in combination with structural models to conduct equilibrium policy evaluations. The social experiment we consider is the Canadian Self-Sufficiency Project (SSP). We start by providing some details on the SSP experiment and then outline our approach for conducting a general equilibrium evaluation of the policy it embodied. ${ }^{12}$

The SSP experiment focused on long-term IA recipients. ${ }^{13}$ The universe for the experiment was long-term single parent IA recipients ages 19 and older in British Columbia and New Brunswick from November 1992 to March 1995. This universe was sampled at random. Of those selected, 6,028 recipients volunteered to participate in the experiment and were subsequently placed in treatment and control groups by random assignment. ${ }^{14}$ Individuals

\footnotetext{
${ }^{12}$ For comprehensive details on the Self-Sufficiency Project, see Michalopoulous, et al. (2002).

${ }^{13}$ In particular, individuals had to receive IA in at least 11 months during the last year including the current month in order to be included in the experiment.

${ }^{14}$ Kamionka and Lacroix (2002) examine the potential for randomization bias in the (partial equilibrium) experimental impact estimates due to refusals to participate in the experiment. They find evidence that the published estimates understate the true impact of the SSP treatment.
} 
assigned to the treatment group were informed that they were to receive an earnings supplement if they found a full-time (30 hours per week) job within one year and left income assistance. The supplement received by members of the treatment group equaled one-half of the distance between the earnings of the recipient and a benchmark earnings level, set at $\$ 37,000$ in British Columbia and at $\$ 30,000$ in New Brunswick..$^{15}$ Once eligible, individuals could receive the supplement for up to three years. Individuals in the treatment group who were not able to secure full-time employment within the twelve months following random assignment become ineligible to receive the supplement. Individuals in the control group were never eligible for the supplement.

The data contain information on 5,686 individuals from the main study who responded to the 18 and 36-month follow-up surveys: 2,827 control group members and 2,859 treatment group members. We imposed the following additional sample restrictions. First, 280 males were dropped from the sample so that our analysis can focus on a homogeneous group (single mothers) within the study. ${ }^{16}$ Second, 13 observations with inconsistent information in the baseline survey were removed from the sample ${ }^{17}$ and 324 cases with missing information on hours, earnings and other relevant variables in the 18-month follow-up data were eliminated. An additional 476 cases with missing hours and earnings information in the 36-month followup survey were also removed. The remaining sample contains 4,593 respondents, of whom 2,290 are members of the control group and 2,303 are members of the treatment group. ${ }^{18}$ This final sample is the one we use for our policy evaluation.

The policy evaluation we undertake involves the following four stages:

\footnotetext{
${ }^{15}$ No other sources of income affected the calculation of the earnings supplement.

${ }^{16}$ This is a relatively innocuous restriction, as $95 \%$ of the individuals in the SSP experiment are female.

${ }^{17}$ In particular, 7 individuals report their age at the baseline survey to be less than 19 and 6 individuals report having no children. To be included in the study, individuals had to be single parents and at least 19 years of age.

${ }^{18}$ The control group contains 1,061 respondents from New Brunswick and 1,229 from British Columbia, while the treatment group consists of 1,072 and 1,231 respondents from New Brunswick and British Columbia, respectively.
} 
1. Calibrate the model to be consistent with the population targeted in the SSP social experiment using data on the experimental control group and external data sources. This represents the model control group.

2. Introduce the Self-Sufficiency Project in the model as an experiment in much the same way it was implemented in reality. Simulate the behavioral effects of the program in partial equilibrium. This represents the model treatment group.

3. Compare the impact predicted by the model to the mean impact observed in the data. This exercise provides evidence on how well the simulated experiment based on our model replicates the impacts observed in the actual experiment. It is important to emphasize that the partial equilibrium version of the model is the appropriate comparison to the experiment because the experiment only affected a small subset of the economy and as such is not expected to have general equilibrium impacts.

4. If the model is able to capture the response of individuals to the experiment, then proceed to simulate the equilibrium effects of the policy in the model economy for the target population of all low-skill workers.

We now discuss each of these steps in detail.

\subsection{Constructing the model control group}

In this section, we calibrate our model to data on single mothers without completed postsecondary education and to data on the experimental control group. The model is calibrated separately for British Columbia and New Brunswick, the two provinces in which the SSP experiment was implemented. For the sake of brevity, and because they tell the same substantive story, we only report results for British Columbia. A full set of results for New 
Brunswick is contained in a supplement that is available from the authors upon request. ${ }^{19}$ As the SSP experiment affected only a small fraction of the population, we use a partial equilibrium version of the model when generating simulated impacts from the model to compare to the measured impacts from the actual experiment.

The parameters for the partial equilibrium version of the model include monthly income assistance and unemployment benefits ( $b_{a}$ and $b_{u}$, respectively), the wage profile, the size of the labor force $(L)$, the vacancy rate $(V / F)$, the job separation rate $(\delta)$, the discount factor $(\beta)$, and the search friction parameters $\left(c_{a}, c_{u}, z\right)$. Table 2 reports the values used for these parameters.

Monthly income assistance benefits $\left(b_{a}\right)$ for single mothers (by province) are based on the average IA benefits for a single parent with one child during the 1990s, as reported in the National Council of Welfare Reports (2002). Over this period the average monthly income assistance benefit was $\$ 927$. UI benefits $\left(b_{u}\right)$ are set at 55 per cent of average earnings. In British Columbia, the earnings sample is limited to single mothers without completed post-secondary education, as we are attempting to isolate that segment of the labor market most similar to individuals receiving Income Assistance. ${ }^{20}$ The earnings data are based on the usual hourly wage for the latter sub-population in British Columbia, as reported in the monthly Labour Force Survey (1997-2000), assuming a 37.5 hour work week. ${ }^{21}$ Earnings, IA benefits and unemployment benefits are all converted to 1992 dollars using the all-goods CPI. ${ }^{22}$ The resulting monthly unemployment benefit level is $\$ 952$.

The model is homogeneous of degree zero in $L$ and $F$; we can therefore normalize the size of the labor force to 100 without loss of generality. The number of firms in the economy

\footnotetext{
${ }^{19}$ We focus on British Columbia in the paper rather than New Brunswick because a second component of the SSP, the Entry Effects experiment, was only carried out in British Columbia.

${ }^{20}$ Approximately $12 \%$ of the control group in the Self-Sufficiency Project has some post-secondary education.

${ }^{21}$ The Canadian Labour Force Survey is the analogue of the U.S. Current Population Survey.

${ }^{22}$ All figures are reported in 1992 Canadian dollars, where $\$ 1 \mathrm{Cdn}$ is presently equal to about $\$ 0.75$ US.
} 
will be estimated in the baseline model, and is identified using the observed vacancy rate in the economy. Equation (11) determines $V$ endogenously as a function of $F$ and $E$. In order to estimate $F$ we use the additional relationship between $F$ and $V$ given by the vacancy rate $(v)$

$$
\frac{V}{F}=v
$$

The vacancy rate of 3.20 is taken from Galarneau et al. (2001) and is based on the average for the retail trade and consumer services and labor-intensive tertiary manufacturing sectors, both of which have average incomes similar to our sample. Therefore, using equation (11), and for a given value of $E$,

$$
F=\frac{E}{(1-0.032)}
$$

The job separation rate in the model $(\delta)$ is constant and can be directly estimated by the average job tenure for single mothers in British Columbia with no completed postsecondary education in the monthly Labour Force Survey (1990-2000). Job tenure is only reported for individuals currently employed in the data; we do not have direct information on separations. However, average job tenure is observed and in the model is equal to

$$
\frac{\sum_{t=1}^{\infty} t E(t)}{E}=\frac{E(1) \sum_{t=1}^{\infty} t(1-\delta)^{t-1}}{E(1) \sum_{t=1}^{\infty}(1-\delta)^{t-1}}=\frac{1}{\delta}
$$

Average job tenure in the Labour Force Survey (LFS 1990-2000) for this group is 46.68 months; therefore the monthly separation rate equals $0.0214 .^{23}$

We use parameter estimates for our search cost function from Christensen, Lentz, Mortensen, Neumann and Wervatz (2002), whose estimates of the elasticity of search costs imply $z=1.8457$, and we set the monthly discount factor $\beta$ equal to 0.9835 , corresponding to an annual discount factor of 0.82 as in Davidson and Woodbury (1993). We assess the sensitivity of our results to the values of these parameters in Section 6 below. The costs

\footnotetext{
${ }^{23}$ This measure of job tenure does not take quits into account. As a result, we may overestimate the job separation rate as individuals moving between jobs because of quits report holding jobs of shorter durations.
} 
of search are allowed to differ depending on whether individuals are receiving UI benefits or IA in order to capture the notion that searching may be less costly while unemployed. For example, unemployed individuals may have access to better search technologies through unemployment offices than do IA recipients, which would be consistent with $c_{a}>c_{u}$.

To identify the search friction parameter $c_{a}$ we use the IA-to-work transition rate, $m(0)$, directly observed from the SSP control group. The data on the control group do not provide information on the transition from unemployment to work necessary to identify the search friction for this group $\left(c_{u}\right)$. Instead we use the search friction implied by the equilibrium model calibrated to the low-skill labor force outlined below in Section 4.

Next we must specify the length of time a worker is eligible for unemployment insurance benefits. The length of the UI benefit eligibility period in Canada depends on the unemployment rate in the region of residence (British Columbia in this case) and on the worker's previous job tenure. We set the eligibility periods in the model according to the eligibility rules in place during the 1990s. In British Columbia, this implies that a worker is entitled to 5 months of benefits after working 4 months, and to 10 months of benefits after working 9 months or more (Lin 1998).

Finally, we set the minimum wage to 5.50 to match the legislated minimum wage in BC at the beginning of the SSP experiment (Michalopoulos, Tattrie, Miller, Robins, Morris, Gyarmati, Redcross, Foley, and Ford, 2002) and abstract from increases in the minimum wage during the remainder of the experiment. ${ }^{24}$

After calibrating and simulating the model, we select those individuals who received income assistance benefits for at least 12 months. These individuals constitute the simulated model control group.

\footnotetext{
${ }^{24}$ As discussed in Michalopoulos et al. (2002), the minimum wage in British Columbia increased several times following random assignment, from $\$ 5.50$ per hour in November 1992 to $\$ 7.15$ in April 1998. We repeated our analysis using the minimum wage in place at the end of the experiment and found the qualitative results were the same. These results are available from the authors upon request.
} 


\subsection{Constructing the model treatment group}

The following additions are made to the model to incorporate the Self-Sufficiency Project. ${ }^{25}$ First, individuals on IA face several time constraints. IA recipients become eligible for SSP after they have been on income assistance a minimum of 12 months. Once eligible for SSP, individuals have 12 months to find full-time employment in order to receive supplement payments. If an individual secures a job before the eligibility period ends, she can receive the supplement while employed for a maximum of 36 months. Consistent with the SSP treatment implemented in the experiment, individuals have one eligibility period for the treatment during their lifetimes. Once the eligibility period for the supplement payments expires, individuals return to the regular IA system. Second, eligible individuals who find work receive supplement payments that are a function of their wage upon obtaining employment.

In order to mimic the experimental design of the SSP, we simulate the model in partial equilibrium, using a fixed wage profile. In addition, we assume that (as in the experiment) individuals do not anticipate the SSP treatment. We then solve for the re-employment probabilities of a random sample of individuals on IA for at least 12 months. These individuals constitute the simulated model treatment group.

\subsection{Comparing the outcomes of the model experiment with the outcomes of the social experiment}

We now compare the predicted partial equilibrium effects of SSP to those found in the SSP experiment. This comparison represents an empirical test of our model, in the same spirit as the comparisons of experimental and non-experimental partial equilibrium estimates in LaLonde (1986) and other, similar papers in the treatment effects literature. It is important

\footnotetext{
${ }^{25}$ Extending the model to include the SSP requires only minor changes. As such, we omit the details from the paper, but describe them in an appendix available from the authors upon request.
} 
to emphasize that we do not use any information on the SSP treatment group in the calibration of our model; we are interested in whether the model can predict the behavior of the treatment group as an informal out-of-sample test.

Figure 1 compares the income assistance survival rates for the control and treatment groups in the SSP experiment and in the model simulation. ${ }^{26}$ The basic pattern matches the experimental data very well. Both the simulation and the experiment indicate that the SSP increases the exit rate from income assistance to work substantially, with the impact ending once eligibility expires. During the 12 months of program eligibility individuals increase their search effort and as a result transit to employment at a faster rate. Once the 12-month eligibility period is over, behavior reverts back to what it was in the absence of the program, and the transition rate to employment returns to exactly what it was in the absence of the treatment. It is very encouraging that the model correctly predicts not only the basic pattern, but also matches the proportion of the treatment group remaining on income assistance 36 months after random assignment.

As an additional test of how well the model predicts behavior we reproduce a second experiment designed to estimate the extent of any delayed exit from income assistance that results from the 12-month SSP qualification period. The delayed exit experiment was a separate experiment conducted on a sample of 3,315 single parents in their first month of IA receipt in the metropolitan area of Vancouver, British Columbia. This sample was randomly assigned to treatment and control groups, where the treatment group was told that they would become eligible for the SSP program if they remained on IA for 12 months.

\footnotetext{
${ }^{26}$ To maintain comparability between our model and the experimental data we condition on not being employed full-time in the month of random assignment and consider exits to full-time employment as the end of an income assistance spell. In the model, receiving income assistance and employment are mutually exclusive states, while in the data they are not. This is due to lags in the receipt of income assistance payments, as well as the definition of full-time employment in the SSP data: "being employed full-time during any portion of the month." Conditioning on not being employed at random assignment gives us an appropriate group for comparison with the model at the expense of dropping the 25 percent who were employed.
} 
The difference between the fraction remaining on IA in the program and treatment groups 12 months after random assignment is estimated by Ford, Gyarmati, Foley, Tattrie and Jimenez (2003) to be 3.9 percentage points with a standard error of 1.4. We conduct the same experiment in our model in partial equilibrium. The model predicts a delayed exit effect of 4.3 percentage points in British Columbia, which is within one-third of the standard error of the effect estimated by Ford et al. (2003). The model is thus able to predict the magnitude of the experimental delayed exit effect quite well.

Comparing the model predictions with the experimental impacts we can see that the model correctly predicts both the degree of delayed exit associated with the expectation of receiving the SSP supplement in the future as well as the increased transition rate into employment that becoming eligible for the SSP program induces. This comparison indicates that the model captures the fundamental dynamics introduced by the SSP policy, which increases our confidence in the policy simulations that follow.

\section{The Equilibrium Impacts of the SSP Policy}

\subsection{Calibrating the equilibrium model}

In the equilibrium analysis, we focus on all IA recipients. We do this for two reasons. First, it simplifies our analysis substantially. If the SSP were limited to single mothers (or single parents), the model would have to be extended to allow for two types of IA recipients: those potentially eligible for the SSP supplement and all the rest. This extension would require a large increase in the size of the state space. Second, if the SSP policy were adopted, it would likely apply to all IA recipients rather than just to single parents, both for political reasons related to equal treatment and to avoid incentive effects of SSP on marital dissolution and on out-of-wedlock childbearing.

The calibration of the general equilibrium version of the model differs from that of the 
partial equilibrium version of the model in two ways. First, because the relevant group to be studied within the model is no longer limited to single mothers, we recalibrate wages, the job separation rate $(\delta)$, unemployment benefits, and IA benefits. We approximate the low-skill population most likely to be affected by the policy by individuals with less than a post-secondary level of education. Table 3 presents the values of the calibrated parameters; we discuss them in more detail below. The calibrated IA benefits equal $\$ 695$ in British Columbia. $^{27}$ The calibrated UI benefit level equals $\$ 1,174$.

Second, we calibrate the parameters for firm behavior and equilibrium wage determination and impose the steady state conditions. The fractions of the relevant population in each labor force state $(A, U$, and $E)$ in British Columbia are estimated from the 1993-94 longitudinal wave of the Survey of Labour Income Dynamics (SLID) ${ }^{28}$ Unlike the LFS, the SLID has separate data on IA and UI benefit receipt. We adopt the following definitions in the data in order to maintain consistency with the model. We define employed workers as individuals who are employed in the first week of the month and report no UI or IA benefits during the month. Unemployed workers are defined as individuals who are either unemployed or not in the labor force and report receiving UI benefits. Finally, IA recipients are individuals who are either unemployed or not in the labor force and report receiving IA. We exclude all individuals who do not fit these criteria, such as those who report working full time and receiving either UI or IA benefits. Similarly, we exclude those reporting that they are unemployed or not in the labor force, but not receiving any UI or IA benefits. ${ }^{29}$

Third, we calibrate the match surplus for each of the first 48 months of job tenure

\footnotetext{
${ }^{27}$ IA benefits by province are provided for the sub-groups of single employable persons, persons with disabilities, single parents with one child, and couples with two children. We take a weighted average for these groups, with the weights reflecting their size in the IA population. The population shares are based on those reported for British Columbia in Barrett and Cragg (1998).

${ }^{28}$ The SLID is the Canadian analogue of the U.S. Survey of Income and Program Participation.

${ }^{29} 71$ per cent of the individuals in the data fit into one of these three mutually exclusive categories. Of those who do not, 80 per cent report being either unemployed or not in the labor force, but do not report receiving either UI or IA benefits.
} 
$(S(1)-S(48))$, with one additional match surplus for all jobs of a longer duration $(S(49))$.

We do not directly observe the match surplus; however, we do observe the average wage for workers with different tenure levels in the data. We can therefore use the wage and tenure information from the LFS for the sample of individuals in British Columbia without completed post-secondary education to infer the match values in the baseline economy. In particular, we estimate a wage profile that is cubic in job tenure and then determine the match values in the model that generate the equilibrium wage profile observed in the data. It is important to emphasize that we assume the match values $S(t)$, but not wages, are invariant to policy changes. In particular, the policy changes we consider change the value of the outside options of workers and firms, and thus the way the match value is divided, but not the total value of the match itself. ${ }^{30}$

The first period of employment in the model differs from later periods of employment, as the model allows starting wages to differ depending on whether the worker's outside option is IA or unemployment. However, it is not possible to separate out the starting wages in the data for individuals with different outside options. In the model, all matches are assumed to have the same match surplus value, but workers may receive different wages, as they face different outside options when bargaining with firms. Therefore, when estimating the starting wages for workers in each of the first $\bar{u}$ periods of employment, we restrict the average of the wage for each month in the model to equal the average wage for a worker with the corresponding tenure in the data. The cost of posting a vacancy $(\xi)$ is calibrated so that the value of a vacancy equals zero. The job separation rate $(\delta)$, the search cost elasticity $(z)$, the discount factor $(\beta)$, the size of the labor force $(L)$ and the vacancy rate $(v)$ are calibrated as in Section 3.1.

Given $b_{a}, b_{u}, L, E, U, A, F, z, \delta, \beta$, and data on wages, the baseline model is a system

\footnotetext{
${ }^{30}$ This assumption would be invalid if the policy experiments considered involved changing the productivity of worker-firm matches.
} 
of 377 equations and unknowns. Solving the baseline model yields estimates for $c_{a}, c_{u}, \xi$, $S(1)-S(49)$, and starting wages $w(t, i)$ for each unemployment insurance eligibility status. ${ }^{31}$

\subsection{The equilibrium model with SSP}

In this section we incorporate the SSP program as policy in the model. There are two key differences between the partial equilibrium analysis of the last section and the following simulations. First, all workers and firms are now aware of the SSP program and will include this information in their decision making processes; as a result, the SSP program will now have feedback effects, just as the unemployment insurance and income assistance program have feedback effects. Second, the Self-Sufficiency policy now applies to all IA recipients, rather than just to single parent IA recipients as in the experiment.

Our discussion regarding the implementation of SSP as policy focuses on the three questions raised in the introduction. First, does an increase in the employment rate for IA recipients come at the expense of reduced employment for others in the labor market? Second, what impact does offering an earnings supplement have on the distribution of wages in the economy? Finally, does the existence of the SSP program delay exit from IA during the pre-qualifying period? We now discuss the answer to each question in turn.

\subsection{The Displacement Effect}

The top half of Table 4 presents the expected durations of joblessness. As expected, the average duration of income assistance spells is substantially reduced under the SSP program, as SSP-eligible individuals face greater incentives to exit the IA program. The model predicts a decrease in expected IA duration of approximately 32 days (1.1 months). In contrast, the expected duration of unemployment spells for those eligible for the maximum number of months increases by approximately 3 days (0.09 months). In essence, the policy

\footnotetext{
${ }^{31}$ Estimates of the match surplus values and wages are available from the authors upon request.
} 
change increases the likelihood that unemployed workers exhaust their UI benefits and transit to IA, as unemployed workers are displaced in the labor market by IA recipients. The total jobless duration increases for those who begin a spell in unemployment, while the total jobless duration decreases for those exiting employment to IA.

The last two rows of Table 4 indicate that employment rates and vacancies decline in British Columbia following the introduction of SSP. Employment falls within the model due to the relationship between wage bargaining and the minimum wage (discussed below). In particular, because firms are constrained to pay at least the minimum wage and the value of IA increases for workers because of the presence of SSP, workers have a higher threat point. As a result, firms are not able to extract the surplus introduced by the SSP when bargaining with workers.

\subsection{The Wage Effect}

As discussed in Section 3, starting wages differ depending on whether the worker transits from IA or UI and depending on the length of the unemployment spell. Once the SSP is in place, starting wages also differ depending on whether the worker is transiting from an SSP-eligible state. Table 5 displays the average earnings, over the first six months of employment, for workers transiting to employment from selected states. Several patterns are worth discussion.

First, individuals eligible to receive supplement payments in British Columbia experience only a 5\% (834-938/938) reduction in wages. The reason supplement-eligible workers do not experience large reductions in wages is that firms are constrained to pay them at least the minimum wage. The income of workers receiving supplement payments, as a result, rises substantially: for example, before the policy change an individual in British Columbia that transited to employment from the first period of IA would earn, on average, $\$ 938$ per 
month over the first six months of employment. In contrast, the same worker would expect to receive $\$ 1,989$ in earnings and supplement payments if he or she transits to employment during the first month of eligibility for the SSP supplement.

Surprisingly, other workers experience an increase in wages following the introduction of the SSP. For example, UI recipients who are one month from exhausting benefits receive starting wages that are $13 \%$ higher after the introduction of the SSP program. One's initial intuition may be that they should receive a lower wage; the reason they do not is because supplement-eligible workers do not experience a large decline in wages because of the minimum wage. As a result, the introduction of the supplement does not result in firms receiving a larger share of the match surplus. At the same time, the value of entering IA has increased due to the introduction of the supplement. As a result, the outside options of UI recipients and IA recipients who are not eligible to receive the supplement improve.

\subsection{Delayed Exit Effects}

As discussed earlier, the equilibrium unemployment rate increases slightly with the introduction of the SSP program, the result of a lower re-employment probability for unemployed workers. The fall in re-employment probabilities for unemployed workers is due in large part to the fact that unemployed workers exert less search effort after the policy change. The difference in search effort for unemployed workers in the baseline and in the model following the introduction of the Self-Sufficiency policy is presented in Figure 2. In general, search effort for unemployed workers increases in the months leading up to unemployment benefit exhaustion. However, because the value of transiting to IA has increased following the policy change, search effort for unemployed workers in the SSP world does not rise to the same extent as it did in the baseline economy. As a result, a larger fraction of unemployed workers transit from unemployment to IA after the policy change. 
The search behavior of IA recipients also changes following the policy change. Figure 3 compares the survival rates for individuals entering IA in the baseline world and the SSP world. In the presence of the SSP, the survival rate is higher in the first 15 months than in the base case. This finding is indicative of the presence of delayed exit effects, due to the fact that individuals have incentives to remain on IA long enough to become eligible to receive the supplement. Although survival rates are higher in the first 15 months of an IA spell with the SSP, the subsequent decrease in survival rates that results from the increased search effort of supplement-eligible IA recipients outweighs the delayed exit effects, as the average duration of IA spells declines following the imposition of the SSP.

\subsection{A Comparison of the Simulated Impacts in Partial Equilibrium and General Equilibrium}

To gauge the importance of general equilibrium effects in the simulated economy, we compare the simulated impacts of the Self-Sufficiency program in partial equilibrium to the general equilibrium effects highlighted above. The difference in survival rates for IA recipients in the partial equilibrium model as compared to the general equilibrium model are presented in Figure 4. The impact of the policy change is slightly greater in the partial equilibrium version of the model. This result is not surprising for two reasons. First, wages do not fall in the partial equilibrium model after the workers become eligible for the supplement. Second, re-employment probabilities do not decline in response to the increased flow of IA recipients into employment. Both factors are consistent with greater incentives to exit IA for employment when equilibrium effects are not taken into account. Our results are consistent with the findings from the literature discussed in the introduction of smaller impacts of policy changes when equilibrium effects are taken into account (Davidson and Woodbury, 1993; Heckman, Lochner and Taber, 1998). It should be noted that, because of the assumption of free entry for firms and constant returns to scale in production, our 
simulation likely captures a lower bound on the general equilibrium effects.

\section{Reconsidering the Costs and Benefits of the Self-Sufficiency Project}

In this section, we look at the benefits of implementing the SSP policy relative to the costs. To highlight the importance of equilibrium effects, we conduct our cost-benefit analysis using both the partial equilibrium and the general equilibrium results. Our analysis has two limitations worth noting. First, SSP was found to have both positive and negative effects on other variables of interest such as marriage and child outcomes (Michalopoulos et al., 2002). We ignore outcome variables other than earnings, as they are beyond the scope of this paper. Second, we do not consider any additional costs or benefits associated with the process of moving from the baseline steady state to the SSP steady state.

We start with the partial equilibrium cost-benefit analysis. In this case, the following assumptions are imposed. First, the only individuals who change their behavior in response to the policy change are those who have been on income assistance for 12 months. Second, any jobs obtained as a result of the SSP program are 'new jobs', leading to an increase in aggregate output. Finally, wages do not change from the baseline economy. In other words, we assume that there are no displacement effects, no delayed exit effects, and no wage effects.

Our cost-benefit analysis, presented in Table 6, draws on SSP program cost information presented in Michalopoulos et al. (2002). First, we calculate the direct costs of administering the Self-Sufficiency policy. Michalopoulus et al. (2002, Table 7.7) estimate that the net average cost per individual eligible for the SSP program is $\$ 1,367$. In addition, SSP increases the costs of administering other transfer programs and generates management information systems costs totaling $\$ 251$ per eligible person in British Columbia. In the first two columns 
of Table 6 , the total program costs for each province are subsequently multiplied by 1.5 , an estimate of the marginal social cost of a tax dollar. ${ }^{32}$ The estimated cost of SSP program services weighted by the number of individuals eligible for SSP in the partial equilibrium version of our model is $\$ 128,276$ per 1000 individuals in the low-skill population of British Columbia (hereafter "per 1000").

Second, we calculate the total value of transfer payments in the baseline economy and in the economy with the SSP. We multiply the difference in the value of the transfer payments by the deadweight loss associated with the taxes necessary to finance the difference in transfers, estimated at 0.5. The deadweight loss of the change in transfer payments is therefore estimated as $\$ 493,144$ per 1000 .

Third, we calculate total output in the baseline economy and in the economy with the SSP. In the partial equilibrium version of the model, the value of monthly output increases after the Self-Sufficiency policy is introduced. In particular, we predict output to increase, per 1000 , by $\$ 2,383,891$ in British Columbia after the imposition of the policy change. Finally, we add the direct costs of the program to the social cost of the net increase in taxes resulting from the increase in transfers and then subtract the total from the increase in the value of output. Under these assumptions the SSP program more than pays for itself; there is a net gain from the program of $\$ 1,762,470$ per 1000 .

The equilibrium effects of the policy change the cost-benefit conclusion drawn from the partial equilibrium analysis substantially. Performing the same calculations using the general equilibrium values for output, UI benefit receipt, and IA receipt yields dramatically different cost-benefit estimates. After taking the equilibrium effects into account, the SSP policy yields a net cost of $\$ 1,982,444$ per 1000 . These findings highlight the importance of conducting general equilibrium evaluations of programs, rather than relying solely on the

\footnotetext{
${ }^{32}$ See, e.g., Diewert (1988) and Dalhby (1994) for Canada and Browning (1987) for the U.S.
} 
findings from partial equilibrium social experiments, to guide policy.

The third and fourth columns of Table 6 present the cost-benefit analysis in the case where the marginal social cost of a tax dollar equals zero. This comparison provides a lower bound on the indirect costs of implementing the Self-Sufficiency Project as a wide-scale program. Even neglecting the marginal social cost of taxes, our model indicates that in general equilibrium the benefits of the SSP do not cover its costs.

\section{Sensitivity Analysis}

Table 7 presents evidence on the extent to which our results are sensitive to the choice of the discount factor $(\beta)$ and the elasticity of search costs with respect to search effort $(z)$. It is worth emphasizing that the search friction parameters $c_{a}$ and $c_{u}$ are re-calibrated in the baseline model for each combination of $\beta$ and $z$. Lower values for $\beta$ reduce the incentives of individuals on UI or IA to search as the value of employment falls. Lower values of $c_{a}$ and $c_{u}$ are required to match the observed transitions into employment from unemployment and income assistance. A similar argument holds for $z$. If search costs become more elastic (a higher value for $z$ ), then lower search costs are necessary to match the transition into employment. The re-calibrated values for $c_{a}$ and $c_{u}$ are presented in the top four rows of Table 7.

First, we consider the sensitivity of our partial equilibrium measure of the estimated impact of SSP on income assistance survival rates. For comparison purposes, we also present the experimental impact constructed from the data. Lowering the discount factor increases the simulated impact of the policy in partial equilibrium. This occurs because lower values of $c_{a}$ and $c_{u}$ associated with the decrease in the discount factor result in a

higher exit rate from IA. As search costs become less elastic with respect to search effort, the shape of the cost function changes such that the simulated IA survival rate is greater 
than its experimental counterpart during the 12 months of supplement eligibility. The consistency of Davidson and Woodbury's (1993) estimate of the discount factor and of the search elasticity parameter estimated by Christensen et al. (2002) with the behavior of participants in the Canadian SSP is quite striking.

Next, we consider the sensitivity of the general equilibrium program evaluation to changes in the parameters outlined above. In general, the predicted labor force composition is relatively insensitive to the changes in parameter estimates, as are the number of firms and vacancies. It is also important to note that the cost-benefit conclusions do not change in any of the specifications: the partial equilibrium analysis consistently results in a net gain from the SSP program and the general equilibrium analysis consistently reports a net loss.

\section{Alternative Versions of the Self-Sufficiency Policy}

One of the main advantages to the approach taken in this paper is that we are able to explore the implications of changing the parameters of the SSP policy within our framework. To this end, we consider three alternative versions of the policy and simulate the predicted outcomes of each version in general equilibrium. First, we consider changes in the generosity of the earnings supplement for eligible income assistance recipients. In particular, we reduce the earnings ceiling by $25 \%$. Second, we reduce the supplement payment period from 36 months to 12 months. Finally, we require new IA recipients to remain on IA for 24 months, as opposed to 12, in order to qualify for SSP. Results of each policy experiment are presented in Table 8.

We find that all of the changes we examine improve the cost-benefit performance of the SSP in general equilibrium without reductions in employment. This finding results from reductions in the delayed exit effect: individuals are less willing to exhaust their 
unemployment benefits or to remain on IA for longer periods as SSP becomes less generous.

\section{Conclusion}

This paper makes three main contributions to the literature. First, we add to the small but growing literature that uses structural equilibrium models to study the general equilibrium effects of labor market interventions. Except in unusual cases, as when a policy is implemented differently in separate jurisdictions of sufficient number to allow econometric analysis, estimating general equilibrium effects requires a structural model.

The second contribution is methodological: we show how evidence from social experiments can be used in combination with structural models to perform convincing policy analysis. In so doing, we extend the literature starting with LaLonde (1986) that uses experimental data to benchmark non-experimental evaluation estimators. In particular, we consider the ability of a model, fit to an experimental control group, to match the experimental treatment group as an informal test of the model. Our model passes both versions of this test. The caveat is that the SSP experiment considered here only allows for direct testing of the partial equilibrium aspects of the model. Because the Self-Sufficiency Project has not been implemented on a wide scale, it is not possible to conduct out-of-sample tests regarding the general equilibrium effects of the program. ${ }^{33}$ Nonetheless, our research, together with the recent paper by Todd and Wolpin (2003), indicates that the combination of social experiments and structural models of labor market interventions represent a powerful tool for program evaluation.

The final contribution consists of our empirical findings on the general equilibrium effects of the SSP. This program represents a special case of a broad class of interventions designed to "make work pay" for individuals collecting government benefits. Such interventions have

\footnotetext{
${ }^{33}$ Alternative experimental designs might capture some general equilibrium effects; we thank Ken Wolpin for making this point.
} 
received a great deal of academic and policy attention in recent years. We find that equilibrium wages fall for those treated by the program after the introduction of the earnings supplement, as workers are willing to accept lower starting wages so as to benefit from the supplement payments. However, wages of other workers in the economy increase slightly as the existence of the SSP, along with the minimum wage, increases the threat point of workers. Furthermore, the simulation results indicate the presence of delayed exit effects, as a higher fraction of individuals remain on IA to become eligible for the supplement after the policy change. All these effects have important implications for the cost-benefit performance of the SSP policy; we find that taking account of the general equilibrium effects reverses the cost-benefit calculation from the partial equilibrium experiment. 


\begin{tabular}{|c|c|}
\hline$A$ & Steady state number of workers on social assistance \\
\hline$b_{a}$ & Social assistance benefits \\
\hline$b_{u}$ & Unemployment insurance benefits \\
\hline$c_{a}$ & $\begin{array}{l}\text { Parameter capturing the disutility of search effort in the } \\
\text { cost of search function for social assistance }\end{array}$ \\
\hline$c_{u}$ & $\begin{array}{l}\text { Parameter capturing the disutility of search effort in the } \\
\text { cost of search function for unemployed }\end{array}$ \\
\hline$E$ & Steady state number of employed workers \\
\hline$E(t, i)$ & $\begin{array}{l}\text { Steady state number of employed } \\
\text { workers eligible for } i \text { unemployment insurance benefit months in jobs of tenure } t\end{array}$ \\
\hline $\bar{E}$ & Steady state number of workers no longer experiencing wage growth \\
\hline$F$ & Number of firms (jobs) \\
\hline$L$ & Total labor force \\
\hline$m(0)$ & $\begin{array}{l}\text { Conditional probability a social assistance recipient } \\
\text { finds a job and transits to employment next period }\end{array}$ \\
\hline$m(i)$ & $\begin{array}{l}\text { Conditional probability of re-employment with } i \\
\text { months of unemployment benefits remaining }\end{array}$ \\
\hline$p(0)$ & Search effort for those on social assistance \\
\hline$p(i)$ & Search effort for the unemployed with $i$ benefit months remaining \\
\hline$q(i)$ & $\begin{array}{l}\text { Firm's probability of meeting a potential worker } \\
\text { with } i \text { months of unemployment benefits remaining }\end{array}$ \\
\hline$S(t)$ & Match surplus for a worker firm match of tenure $t$ \\
\hline$T$ & Match tenure beyond which match surplus no longer increase \\
\hline$I$ & $\begin{array}{l}\text { Number of months required to } \\
\text { qualify for minimum unemployment insurance benefits }\end{array}$ \\
\hline$\underline{u}$ & Minimum number of unemployment benefit months \\
\hline $\bar{u}$ & Maximum number of unemployment benefit months \\
\hline$U$ & $\begin{array}{l}\text { Steady state number of workers receiving } \\
\text { unemployment insurance benefits }\end{array}$ \\
\hline$V$ & Steady state number of vacancies \\
\hline$V^{A}$ & The value function for a worker on social assistance \\
\hline$V^{E}(t, i)$ & $\begin{array}{l}\text { The value function for an employed worker in the } \\
t^{\text {th }} \text { period of employment with unemployment benefit eligibility } i\end{array}$ \\
\hline$V^{U}(i)$ & $\begin{array}{l}\text { The value function for an unemployed worker with } \\
i \text { months unemployment insurance benefits remaining }\end{array}$ \\
\hline$w(t, i)$ & $\begin{array}{l}\text { The wage for a worker in the } t^{t h} \text { month of employment } \\
\text { with unemployment eligibility } i\end{array}$ \\
\hline$\underline{w}$ & Minimum wage \\
\hline$z$ & The elasticity of search cost with respect to search effort \\
\hline$\beta$ & Discount factor \\
\hline$\delta$ & Exogenous job separation rate \\
\hline$\lambda$ & $\begin{array}{l}\text { The average number of applications filed by workers } \\
\text { at each firm }\end{array}$ \\
\hline & The per period cost to a firm of posting a vacancy \\
\hline$\Pi^{E}(t, i)$ & $\begin{array}{l}\text { Firms' expected future profit from a match of tenure } t \text {, } \\
\text { with a worker with unemployment eligibility } i\end{array}$ \\
\hline$\Pi^{V}$ & Firms' value of a current vacancy \\
\hline
\end{tabular}


Table 2: Moments and Parameters for Single Mothers without Completed Postsecondary Education

\begin{tabular}{lr}
\hline \hline Income assistance benefits, monthly $\left(b_{a}\right)^{1}$ & 927 \\
Unemployment benefits, monthly $\left(b_{u}\right)^{2}$ & 952 \\
UI qualifying months ${ }^{3}$ & \\
$\quad$ Minimum & 4 \\
$\quad$ Maximum & 9 \\
UI benefit months & 5 \\
$\quad$ Minimum $(\underline{u})$ & 10 \\
$\quad$ Maximum $(\bar{u})$ & 46.68 \\
Average job tenure, months $(1 / \delta)^{4}$ & 10.65 \\
Average hourly wage & 11.12 \\
Average wage, tenure $>48$ months & \\
Wage growth equation $w(t)=$ & $-0.000378 t^{2}$ \\
& $+6.10 e-7 t^{3}$ \\
Vacancy rate $(V / F)^{6}$ & 5.50 \\
Exogenous job separation rate $(\delta)^{7}$ & \\
Minimum wagticity of search costs w.r.t effort $(z)^{9}$ & 3.20 \\
\hline \hline
\end{tabular}

Notes: All values are in 1992 Canadian dollars. 1. National Council of Welfare (2002). 2. Unemployment benefits are based on 55 per cent of average monthly earnings from Labour Force Survey (1997-2000). 3. Information on EI eligibility rules is from Lin (1998). 4. Labour Force Survey (1997-2000). 5. Minimum wage at the beginning of the the SSP experiment (Michalopoulos 2002). 6. Galarneau et al. (2001), based on the average for retail trade and consumer services and labor-intensive tertiary manufacturing sectors. 7. Inverse of average job tenure in the Labour Force Survey (1997-2000). 8. This corresponds to an annual discount rate of 0.82, the rate used for all figures and tables in Davidson and Woodbury (1993). 9. From Christensen, Lentz, Mortensen, Neumann, and Wervatz (2002). 
Table 3: Moments and Parameters for the Baseline General Equilibrium Model

\begin{tabular}{lr}
\hline \hline Income assistance benefits, monthly $\left(b_{a}\right)$ & 695 \\
Unemployment benefits, monthly $\left(b_{u}\right)$ & 1174 \\
Search costs, income assistance $\left(c_{a}\right)$ & 0.3281 \\
Search costs, unemployment $\left(c_{u}\right)$ & 0.0526 \\
Average job tenure, months $(1 / \delta)$ & 72.91 \\
Employment rate $(E)$ & 90.15 \\
Unemployment rate $(U)$ & 5.80 \\
Income assistance rate $(A)$ & 4.05 \\
& \\
Average hourly wage & 13.14 \\
Average wage, tenure $>48$ months & 16.14 \\
Exogenous job separation rate $(\delta)$ & \\
Monthly discount rate $(\beta)$ & 0.0137 \\
Elasticity of search costs w.r.t effort $(z)$ & 0.9835 \\
Cost of posting a vacancy $(\xi)$ & 1.8457 \\
Number of firms $(F)$ & 9,445 \\
Vacancy rate $(V / F)$ & \\
\hline \hline
\end{tabular}

Notes: See Table 2 for sources. 
Table 4: Labor Force Composition — Baseline and SSP Models

\begin{tabular}{lrr} 
& Baseline & SSP \\
\hline \hline Expected UI duration, months & 5.07 & 5.16 \\
Expected IA duration, months & 31.03 & 29.96 \\
Expected jobless duration, months & 8.33 & 8.73 \\
& & \\
Employment rate & 90.15 & 89.72 \\
Unemployment rate & 5.80 & 5.92 \\
Income assistance rate & 4.05 & 4.36 \\
& & \\
Number of firms & 93.13 & 92.67 \\
Number of vacancies & 2.98 & 2.95 \\
\end{tabular}

Notes: The sources for the the baseline values of the labor force status proportions, number of firms and vacancy rate are given in Table 3 . All other values are generated by the model.

Table 5: Average Monthly Earnings — First Six Months

\begin{tabular}{lrr} 
Entering employment from: & Baseline & \multicolumn{1}{c}{ SSP } \\
\hline \hline Maximum months of UI remaining $(U(\bar{u}))$ & 2,070 & 2,085 \\
Last month of UI $(U(1))$ & 972 & 1,097 \\
First month on IA $(A(1))$ & & 967 \\
$12^{\text {th }}$ month on IA $(A(12))$ & & 987 \\
First month eligible for SSP $(S S P(1))$ & & 894 \\
$\quad$ with SSP top-up & & 1,989 \\
Last month eligible for SSP $(S S P(12))$ & & 894 \\
$\quad$ with SSP top-up & & 1,989 \\
IA, no longer eligible for SSP $(A(0))$ & 938 & 967 \\
& & \\
Mean wage & 1,563 & 1,593 \\
SD wage & 407 & 672 \\
Mean income & 1,563 & 1,634 \\
SD income & 407 & 390 \\
\hline \hline
\end{tabular}

Notes: Authors' calculations based on model simulations. 
Table 6: Cost-Benefit Analysis-SSP Applied to All Income Assistance Recipients

Partial General Partial General

Equilibrium Equilibrium $\quad$ Equilibrium Equilibrium

Direct Costs

Marginal Social Cost of $0.5 \quad$ Marginal Social Cost of 0.0

SSP program service $\operatorname{costs}^{1}$

1,367

251

Net SSP admin costs

Number eligible for SSP

Total Direct Costs

Adjusted for $\mathrm{MSC}^{2}$

\section{Indirect Costs}

Change in UI Payments

Change in IA Payments

Change in SSP Payments

Total Change in transfers

Adjusted for $\mathrm{MSC}^{3}$

\author{
Change in output \\ Net gain from program
}

$2,383,891$

$1,762,470$

85,517

128,276
1,367

251

63

102,698

154,047

$\begin{array}{rr}0 & 95,414 \\ -212,553 & 144,375 \\ 1,198,843 & 1,648,983 \\ 986,289 & 1,888,772 \\ 493,144 & 944,386\end{array}$

$-884,011$
$2,383,891$

$-884,011$

$\begin{array}{rr}1,367 & 1,367 \\ 251 & 251 \\ 53 & 63 \\ 85,517 & 102,698 \\ 85,517 & 102,698\end{array}$

$\begin{array}{rr}0 & 95,414 \\ -212,553 & 144,375 \\ 1,198,843 & 1,648,983 \\ 986,289 & 1,888,772 \\ 0 & 0 \\ & \\ 2,383,891 & -884,011 \\ 2,298,374 & -986,709\end{array}$

Notes: Costs are calculated over five years for a labor force normalized to 1000. 1. The direct costs are taken from Michalopoulos et al. (2002, Table 7.7). 2. The direct costs are multiplied by the marginal social cost (MSC) of a tax dollar, estimated to be 1.5 (Diewert 1988; Dalhby 1994; Browning 1987). 3. The marginal social cost of the increase in transfers is just the dead weight loss associated with a tax and transfer system: 0.5 . 
Table 7: Sensitivity to the Choice of $\beta$ and $z$

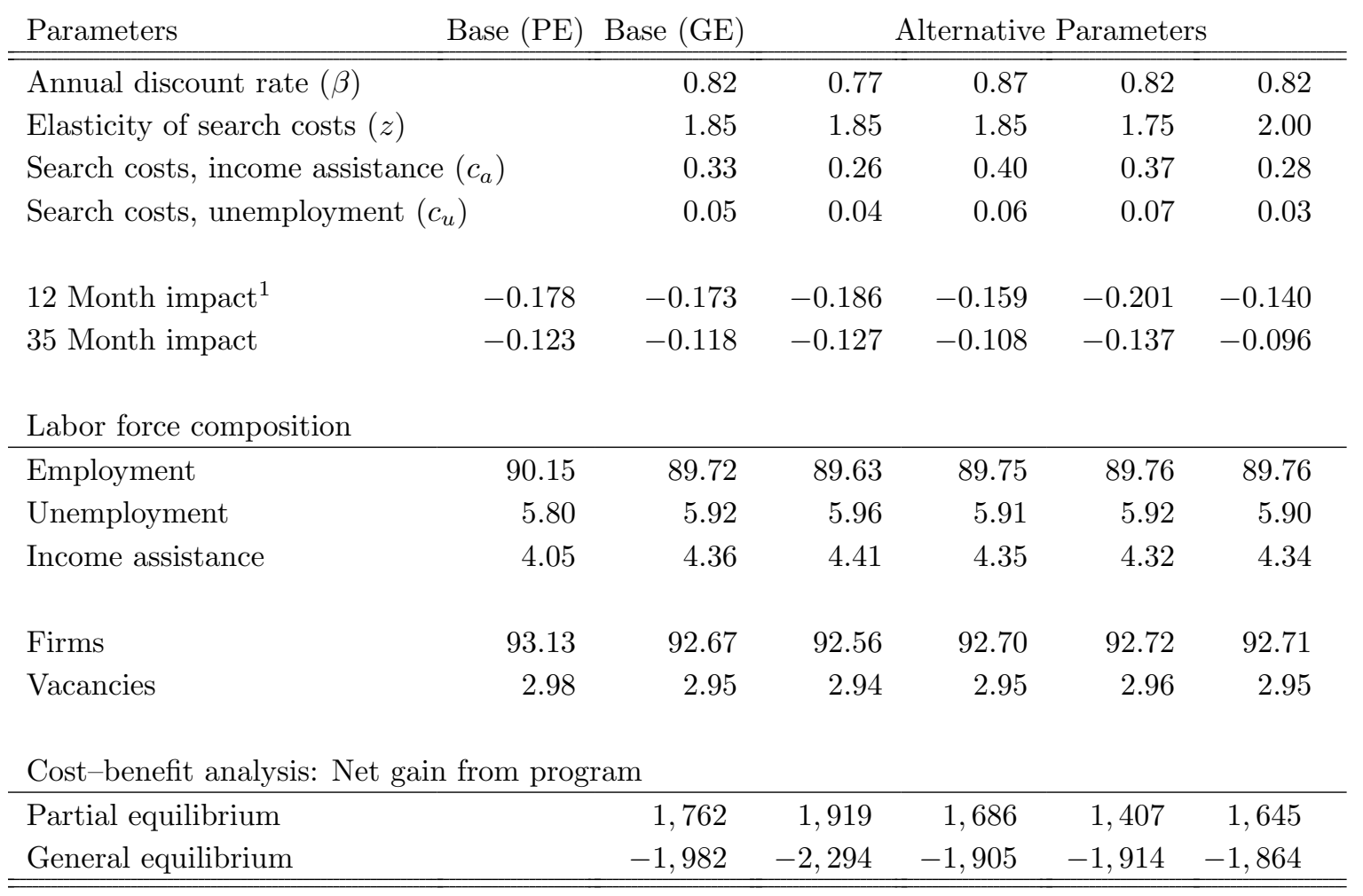

Notes: Authors' calculations based on model simulations. The search friction parameters, $c_{a}$ and $c_{u}$ are re-calibrated in the baseline model for each combination of $\beta$ and $z$. Costs are per capita costs over five years. 1. For the 12 and 35 month impacts the values in the Base (PE) column refer to the impacts estimated using the experimental data. All other values in the table come from model simulations. 
Table 8: Alternative SSP Policy Simulations

\begin{tabular}{|c|c|c|c|c|c|}
\hline & $\begin{array}{l}\text { Base } \\
\text { Case }\end{array}$ & SSP & $\begin{array}{c}\text { Reduced } \\
\text { supplement } \\
\text { by } 75 \%\end{array}$ & $\begin{array}{l}12 \text { month } \\
\text { payment } \\
\text { period }\end{array}$ & $\begin{array}{c}24 \text { months } \\
\text { waiting } \\
\text { period }\end{array}$ \\
\hline & \multicolumn{5}{|c|}{ Labor force composition } \\
\hline Employment & 90.15 & 89.72 & 89.99 & 89.89 & 89.87 \\
\hline Unemployment & 5.80 & 5.92 & 5.85 & 5.87 & 5.86 \\
\hline Income assistance & 4.05 & 4.36 & 4.16 & 4.23 & 4.27 \\
\hline Firms & 93.13 & 92.67 & 92.96 & 92.85 & 92.84 \\
\hline \multirow[t]{2}{*}{ Vacancies } & 2.98 & 2.95 & 2.97 & 2.96 & 2.97 \\
\hline & \multicolumn{5}{|c|}{ Cost-benefit: Net gain from program } \\
\hline Partial equilibrium & & 1,762 & 2,067 & 1,505 & 1,147 \\
\hline General equilibrium & & $-1,982$ & -923 & $-1,465$ & -969 \\
\hline
\end{tabular}

Notes: Authors' calculations based on model simulations. 


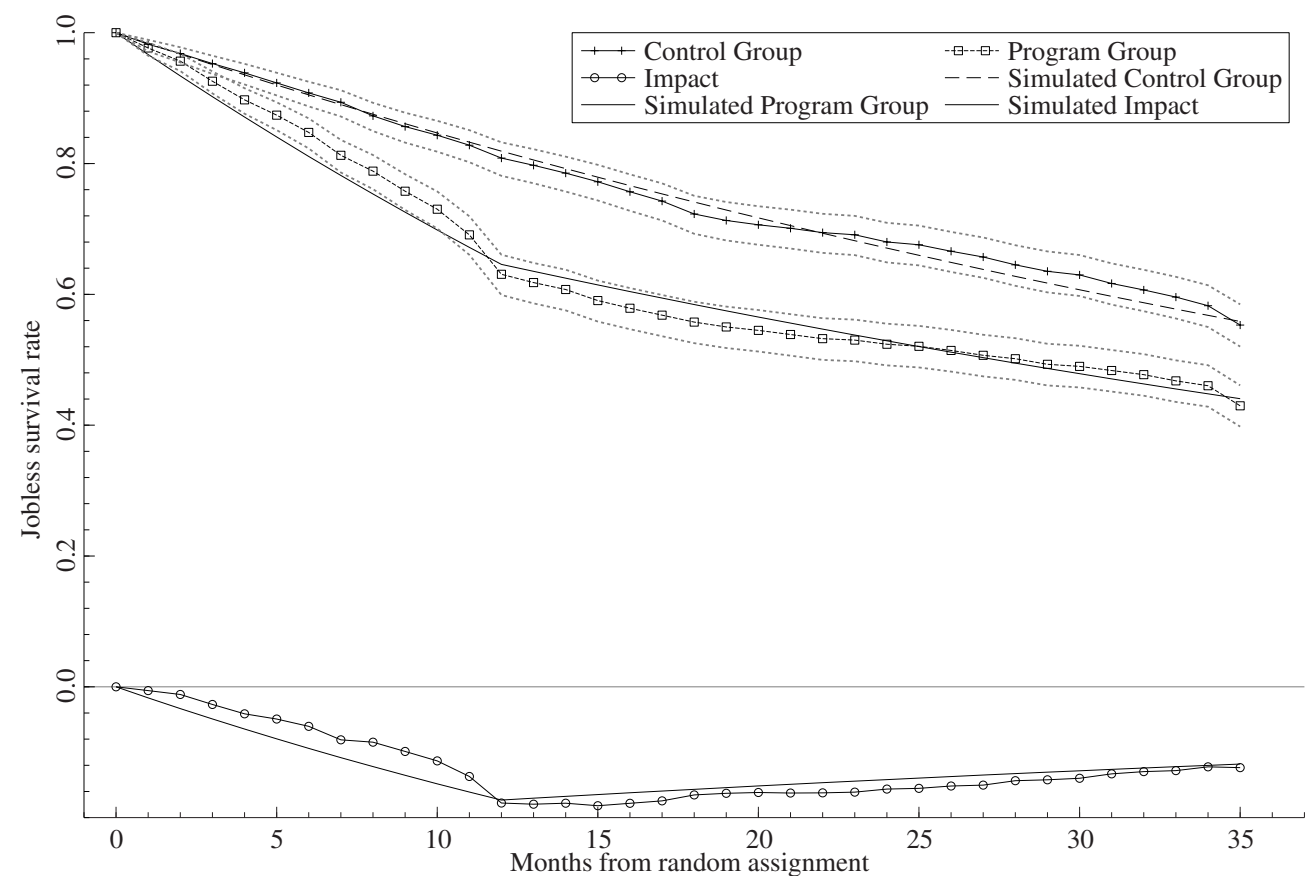

Figure 1: Simulated Partial Equilibrium Impact of SSP. The dotted bands are point wise 95 per cent confidence intervals for the data.

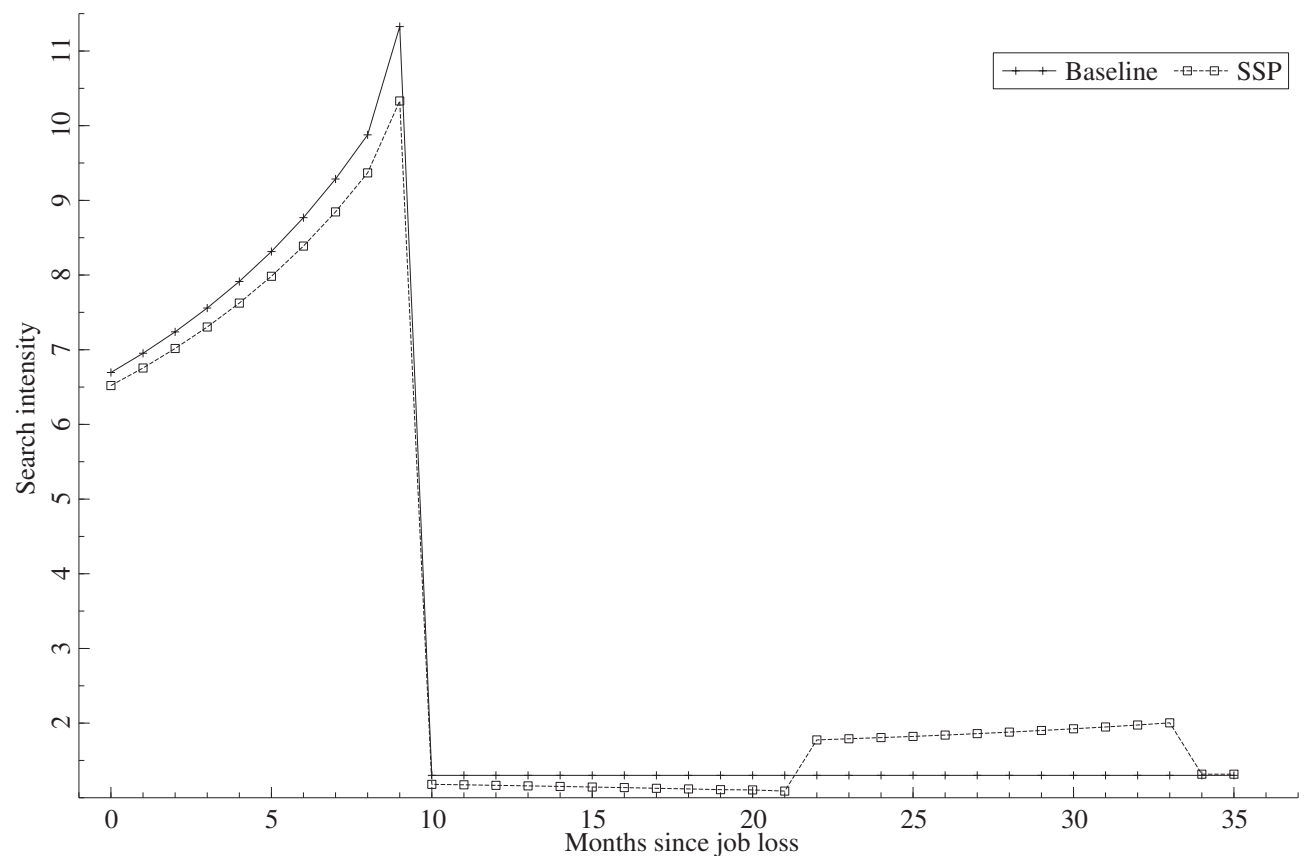

Figure 2: Search Intensity for Those Starting with Maximum Unemployment Benefits 


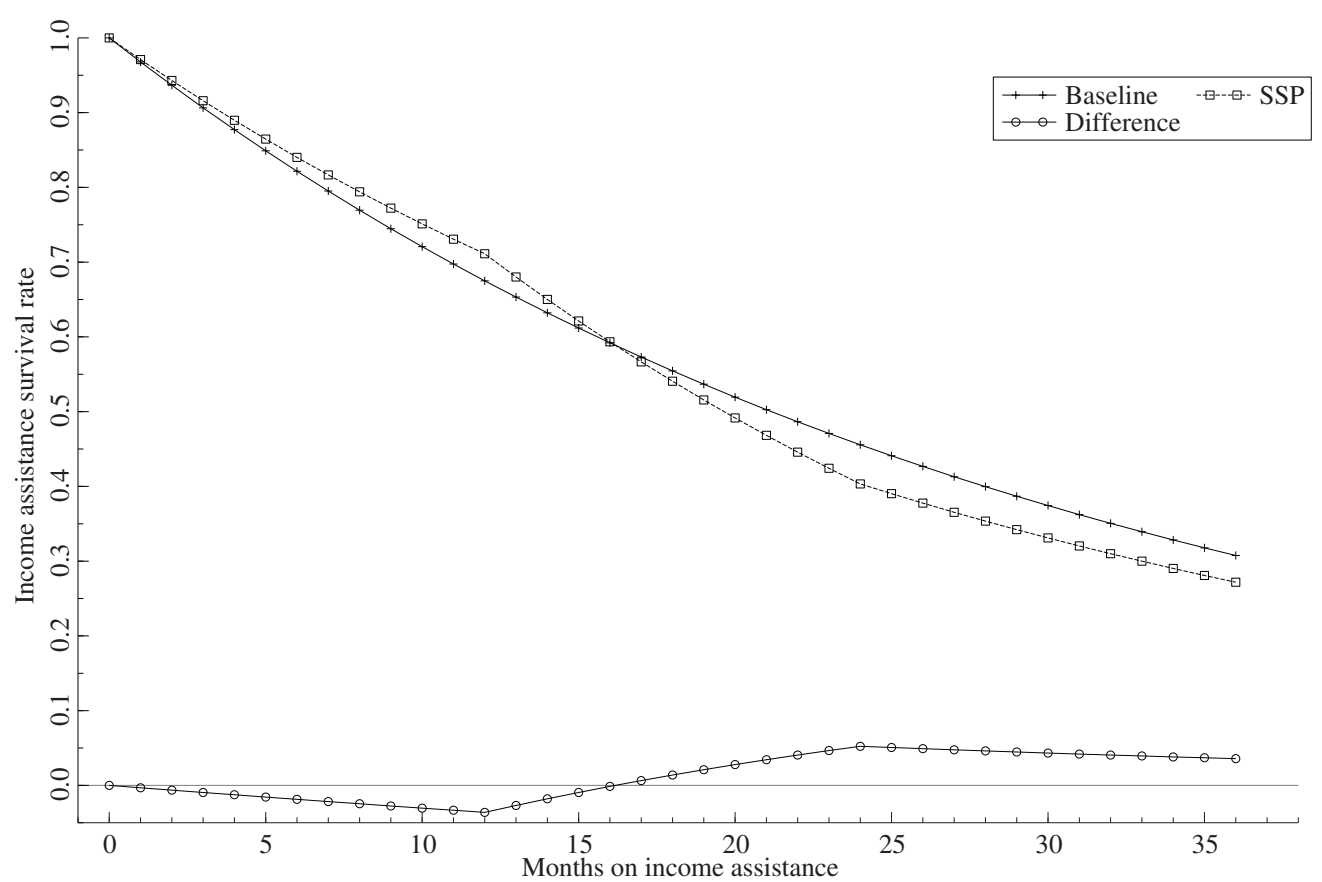

Figure 3: Survival Probability, Starting from Income Assistance

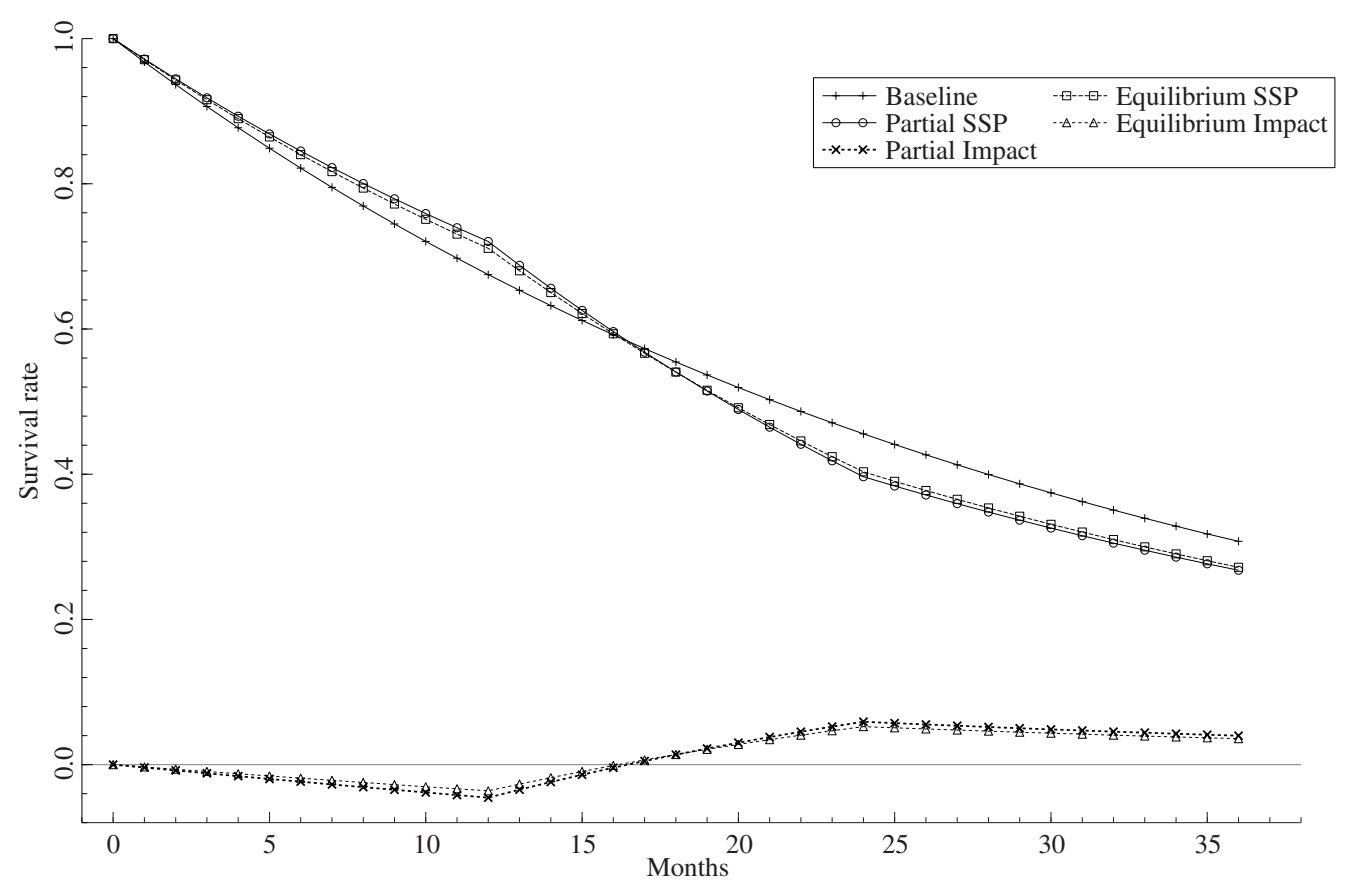

Figure 4: Survival Probability, Partial and Equilibrium Impacts 


\section{References}

[1] Auspos, Patricia; Miller, Cynthia and Hunter, Jo Anna. Final Report on the Implementation and Impacts of the Minnesota Family Investment Program in Ramsey County. New York: Manpower Demonstration Research Corporation, 2000.

[2] Barrett, Garry and Cragg, Michael. "An untold story: the characteristics of welfare use in British Columbia." Canadian Journal of Economics, 31, 1998: 165-88.

[3] Bloom, Dan and Michalopoulos, Charles. How Welfare and Work Policies Affect Employment and Income: A Synthesis of Research. New York: Manpower Demonstration Research Corporation, 2001.

[4] Blundell, Richard, Costa Dias, Monica, and Costas Meghir. "The Impact of Wage Subsidies: A General Equilibrium Approach." Unpublished manuscript, Institute for Fiscal Studies, 2003.

[5] Bos, Hans; Huston, Aletha; Granger, Robert; Duncan, Greg; Brock, Tom and McLoyd, Vonnie; with Crosby, Danielle; Gibson, Christina; Fellerath, Veronica; Magnuson, Katherine; Mistry, Rashmita; Poglinco, Susan; Romich, Jennifer and Ventura, Ana. New Hope for People with Low Incomes: Two Year Results of a Program to Reduce Poverty and Reform Welfare. New York: Manpower Demonstration Research Corporation, 1999.

[6] Browning, Edgar. "On the Marginal Welfare Cost of Taxation." American Economic Review, 77(1), 1987: 11-23.

[7] Calmfors, Lars. "Active Labor Market Policy and Unemployment - A Framework for the Analysis of Crucial Design Features." OECD Economic Studies. 22(1), 1994: 7-47.

[8] Card, David and Hyslop, Dean. "Estimating the Dynamic Effects of an Earnings Subsidy for Welfare-Leavers." Unpublished manuscript, University of California at Berkeley, 2002.

[9] Christensen, Bent Jesper, Lentz, Rasmus, Motensen, Dale T, Neumann, George R., and Wervatz, Axel. "On the Job Search and the Wage Distribution." Unpublished manuscript, Northwestern University, 2002.

[10] Dalhby, Bev. "The Distortionary Effect of Rising Taxes." In Robson, William and Scarth, William, eds., Deficit Reduction: What Pain, What Gain? Toronto: C.D. Howe Institute, 1994.

[11] Davidson, Carl and Woodbury, Stephen A. "The Displacement Effect of Reemployment Bonus Programs." Journal of Labor Economics, 11, 1993: 575-605.

[12] Diamond, Peter A. "Wage Determination and Efficiency in Search Equilibrium," Review of Economic Studies, 49, 1982: 217-228.

[13] Diewert, Irwin. "On Tax Reform." Canadian Journal of Economics. 21(2), 1988: 1-40.

[14] Ferrall, Christopher. "The Dynamics of Income Assistance: Evidence from the SelfSufficiency Project," research report, Social Research Demonstration Corporation, 2000 . 
[15] Ford, Reuben; Gyarmati, David; Foley, Kelly; Tattrie, Doug and Jimenez, Liza. "Can Work Incentives Pay for Themselves? Final Report on the Self-Sufficiency Project for Welfare Applicants." Social Research and Demonstration Corporation, October 2003.

[16] Galarneau, Diane; Krebs, Howard; Morissette, René and Zhang, Xuelin. "The Quest for Workers: A New Portrait of Job Vacancies in Canada." The Evolving Workplace Series. Statistics Canada and Human Resources Development Canada, 2001.

[17] Heckman, James J., Lochner, Lance and Taber, Christopher. "General Equilibrium Treatment Effects: A Study of Tuition Policy." American Economic Review, 88(2), 1998: 381-386.

[18] Heckman, James J. and Smith, Jeffrey. "Evaluating the Welfare State" in Steiner Strom (ed.), Econometrics and Economic Theory in the $20^{\text {th }}$ Century: The Ragner Frisch Centennial. Cambridge University Press for Econometric Society Monograph Series, 1998: 241-318.

[19] Kamionka, Thierry and Lacroix, Guy. "Assessing the Extent of Randomization Bias in the Canadian Self-Sufficiency Experiment." Unpublished manuscript, Université Laval, 2002 .

[20] Lalonde, Robert. "Evaluating the Econometric Evaluation of Training Programs with Experimental Data." American Economic Review, 76(4), 1986: 604-620.

[21] Lin, Zhengxi. "Employment Insurance in Canada: Recent Trends and Policy Changes." Statistics Canada: Analytical Studies Branch-Research Paper Series No. 125, 1998.

[22] Michalopoulos, Charles; Tattrie, Doug; Miller, Cynthia; Robins, Philip; Morris, Pamela; Gyarmati, David; Redcross, Cindy; Foley, Kelly and Ford, Reuben. Making Work Pay: Final Report on the Self-Sufficiency Project for Long-Term Welfare Recipients. Ottawa: Social Research and Demonstration Corporation, 2002.

[23] Mortensen, Dale. "Property Rights and Efficiency in Mating, Racing and Related Games." American Economic Review, 72, 1982: 968-79.

[24] National Council of Welfare. Welfare Incomes, 2000 and 2001, Spring 2002.

[25] Pissarides, Christopher. "Efficient Job Rejection." Economic Journal 94 (suppl.), 1984: 97-108.

[26] Smith, Jeffrey and Todd, Petra. "Does Matching Overcome LaLonde's Critique of Nonexperimental Methods?" Journal of Econometrics, 2004: forthcoming.

[27] Todd, Petra and Wolpin, Kenneth. "Using Experimental Data to Validate a Dynamic Behavioral Model of Child Schooling and Fertility: Assessing the Impact of a School Subsidy Program in Mexico." Unpublished manuscript, University of Pennsylvania, 2003. 